\title{
Erratum to: Involvement of toll-like receptor 9 polymorphism in cervical cancer development
}

\author{
Andrzej Roszak • Margarita Lianeri • \\ Anna Sowińska $\cdot$ Pawel P. Jagodziński
}

Published online: 18 October 2012

(C) Springer Science+Business Media Dordrecht 2012

\section{Erratum to: Mol Biol Rep (2012) 39:8425-8430 \\ DOI 10.1007/s11033-012-1695-8}

Roszak et al., mentioned the study of Pandey et al., 2011, in which they used term "Hindu populations" in the following sentence for "North Indian population" in discussion section.

"In contrast, Pandey et al. [26] showed that the TT genotype of TLR9 (rs352140) displayed borderline significance in increased risk for advanced cervical cancer in a
North India population. These differences in the effect of TRL9 polymorphism on the susceptibility to cervical cancer development between our and Hindu populations may result from racial heterogeneity, the size of the studied groups, and the action of distinct behavioral and environmental factors [33]."

The term "Hindu populations" should be replaced by simply "North Indian population" in this article to avoid any misinterpretation or ambiguity regarding different religions exists in India.

The online version of the original article can be found under doi:10.1007/s11033-012-1695-8.

\section{A. Roszak}

Department of Radiotherapy and Gynecological Oncology,

Greater Poland Cancer Center, Poznan, Poland

\author{
A. Roszak \\ Department of Electroradiology, Poznan University of Medical \\ Sciences, Poznan, Poland
}

M. Lianeri · P. P. Jagodziński ( $\square)$

Department of Biochemistry and Molecular Biology,

Poznan University of Medical Sciences, 6 Święcickiego St,

60-781 Poznan, Poland

e-mail: pjagodzi@am.poznan.pl

A. Sowińska

Department of Computer Science and Statistics,

Poznan University of Medical Sciences, Poznan, Poland 